\title{
LOCAL MINIMUM PRINCIPLE FOR OPTIMIZATION PROBLEMS WITH DIFFERENT TYPES OF CONTROL SYSTEMS SUBJECT TO MIXED STATE-CONTROL CONSTRAINTS
}

\author{
Andrey V. Dmitruk ${ }^{1,2}$, Nikolay P. Osmolovskii ${ }^{3,4,5}$ \\ ${ }^{1}$ Russian Academy of Sciences, CEMI, Moscow, RUSSIA \\ ${ }^{2}$ Lomonosov Moscow State University, Moscow, RUSSIA \\ ${ }^{3}$ University of Technology and Humanities in Radom, Radom, POLAND \\ ${ }^{4}$ Systems Research Institute, Polish Academy of Sciences Warszawa, POLAND \\ ${ }^{5}$ National Research Moscow State University of Civil Engineering, Moscow, RUSSIA
}

\begin{abstract}
This paper discusses the first-order optimality conditions for optimal control problems with two different types of control systems, considered on a fixed time interval: systems of ordinary differential equations and systems of Volterra-type integral equations.
\end{abstract}

Keywords: integral equation, control system, mixed constraints, local minimum principle, weak minimum, stationarity conditions

\section{ЛОКАЛЬНЫЙ ПРИНЦИП МИНИМУМА ДЛЯ ЗАДАЧ ОПТИМИЗАЦИИ С РАЗЛИЧНЫМИ ТИПАМИ УПРАВЛЯЕМЫХ СИСТЕМ ПРИ НАЛИЧИИ СМЕШАННЫХ ОГРАНИЧЕНИЙ НА ФАЗУ И СОСТОЯНИЕ}

\author{
А.В. Дмитрук ${ }^{1,2}$, Н.П. Осмоловский ${ }^{3,4,5}$ \\ ${ }^{1}$ Центральный экономико-математический институт РАН, Москва, РОССИЯ \\ ${ }^{2}$ Московский государственный университет им. М.В. Ломоносова, г. Москва, РОССИЯ \\ ${ }^{3}$ Университет технологий и естественных наук, г. Радом, ПОЛЬША \\ ${ }^{4}$ Институт системных исследований, Польская академия наук, г. Варшава, ПОЛЬША \\ ${ }^{5}$ Национальный исследовательский Московский государственный строительный университет, \\ г. Москва, РОССИЯ
}

\begin{abstract}
Аннотация. В настоящей работе обсуждаются условия оптимальности первого порядка для задач оптимального управления с двумя различными типами управляемых систем, рассматриваемых на фиксированном отрезке времени: системами обыкновенных дифференциальных уравнений и системами интегральных уравнений типа Вольтерра.
\end{abstract}

Ключевые слова: интегральное уравнение, управляемая система, смешанные ограничения, локальный принцип минимума, слабый минимум, условия стационарности

\section{INTRODUCTION}

The aim of this paper is to observe some results on the first-order optimality conditions for a weak local minimum, for control problems with two different types of control systems, considered on a fixed time interval, subject to mixed state-control constraints. We will consider problems with systems of ordinary differential equations (ODEs), and with systems of Volterratype nonlinear integral equations. We will show that the appropriate definition of the Pontryagin function allows to give very similar formulations of the optimality conditions for these two types of systems. The proofs of the observed results 
could be based on one and the same abstract Lagrange multipliers rule.

Let us note that necessary conditions for the weak local minimum in optimal control problems constitute an important stage in derivation of any further necessary optimality condition, including maximum principle or higher order conditions, and thus, they deserve a separate thorough study for each specific class of problems, like it is done in the classical calculus of variations. This is why we focus on these conditions. Following the tradition, we call them stationarity conditions (or local minimum principle).

The paper is organized as follows. In Section 2 we formulate first-order necessary optimality conditions for problems with ordinary differential equations. Section 3 gives such conditions for problems with Volterra-type integral equations. Finally in Section 4 we present an abstract Lagrange multipliers rule, used for the proofs.

\section{OPTIMAL CONTROL PROBLEM WITH ORDINARY DIFFERENTIAL EQUATIONS ON A FIXED TIME IN- TERVAL}

\subsection{Statement of the problem (Problem A)}

We consider the following control system of ordinary differential equations on a fixed time interval $\left[t_{0}, t_{1}\right]$ :

$$
\frac{d x(t)}{d t}=f(t, x(t), u(t))
$$

where $x(\cdot)$ is an absolutely continuous $n-$ dimensional and $u(\cdot)$ a measurable essentially bounded $r$-dimensional vector-function on $\left[t_{0}, t_{1}\right]$. We call $x$ the state variable and $u$ the control variable (or simply the control). We assume that the function $t$ is continuous together with its partial derivatives with respect to $x$ and $u$ on an open set $Q \subset \mathrm{I}^{1+n+r}$.
The problem is to minimize the Bolza-type cost functional

$J=\varphi_{0}\left(x\left(t_{0}\right), x\left(t_{1}\right)\right)+\int_{t_{0}}^{t_{1}} \Phi_{0}(t, x(t), u(t)) d t \rightarrow \min$

on the set of solutions of system (1) satisfying the Bolza-type constraints

$$
\begin{aligned}
& \eta_{j}\left(x\left(t_{0}\right), x\left(t_{1}\right)\right)+ \\
& +\int_{t_{0}}^{t_{1}} \Psi_{j}(t, x(t), u(t)) d t=0, j=1, \ldots, d(\eta), \\
& \phi_{i}\left(x\left(t_{0}\right), x\left(t_{1}\right)\right)+ \\
& +\int_{t_{0}}^{t_{1}} \Phi_{i}(t, x(t), u(t)) d t=0, i=1, \ldots, d(\phi),
\end{aligned}
$$

and the mixed state-control constraints

$$
\begin{aligned}
& F_{i}(t, x(t), u(t)) \leq 0 \\
& \text { for a.e. } t \in\left[t_{0}, t_{1}\right], \quad i=1, \ldots, d(F), \\
& G_{j}(t, x(t), u(t))=0 \\
& \text { for a.e. } t \in\left[t_{0}, t_{1}\right], \quad j=1, \ldots, d(G),
\end{aligned}
$$

where the functions $\varphi_{0}, \varphi_{i}, \eta_{j}$ are defined and continuously differentiable on an open set $P \subset \mathrm{I} R^{2 n}$, and the functions $\Phi_{i}, \Psi_{j}, F_{i}, G_{j}$ are defined and continuous together with their partial derivatives with respect to $x$ and $u$ on an open set $Q \subset \mathrm{I} R^{1+n+r}$. The notation $d(\varphi), d(\eta), d(F)$, etc. stand for the numbers of these functions.

Moreover, we impose the following important Assumption RMC (on the regularity of mixed constraints). The mixed constraints (5)-(6) are regular in the following sense: at any point $(t, x, u) \in Q$ satisfying relations $F_{i} \unlhd 0 \quad \forall i$ and $G_{j}=0 \forall j$, the system of vectors

$$
\begin{aligned}
& F_{i u}^{\prime}(t, x, u), \\
& i \in I(t, x, u), G_{j u}^{\prime}(t, x, u), j=1, \ldots, d(G),
\end{aligned}
$$

is positively--linearly independent, where $I(t, x, u)=\left\{i: F_{i}(t, x, u)=0\right\}$ is the set of active 
indices of mixed inequality constraints at the given point.

Recall that a system consisting of two tuples of vectors $p_{1}, \ldots, p_{m}$ and $q_{1}, \ldots q_{k}$ in the space $\mathrm{I} R^{r}$ is said to be positively-linearly independent if there does not exist a nontrivial tuple of multipliers $\alpha_{1}, \ldots, \alpha_{m}, \beta_{1}, \ldots \beta_{k}$ with all $\alpha_{i} \geq 0$ such that

$$
\sum_{i} \alpha_{i} p_{i}+\sum_{j} \beta_{j} q_{j}=0
$$

The problem (1)-(6) will be called Problem A. Obviously, each pair $(x(t), u(t))$ under consideration must "lie" in the domain $Q$ of the function $f(t, x, u)$, i.e.

$$
(t, x(t), u(t)) \in Q \quad \text { for a.e. } \quad t \in\left[t_{0}, t_{1}\right]
$$

We will need even a stronger condition.

Definition. A pair of functions $w(t)=(x(t), u(t))$ defined on an interval $t \in\left[t_{0}, t_{1}\right]$ (with absolutely continuous $x(t)$ and measurable essentially bounded $u(t))$ will be called a process in Problem A if it satisfies (1) and its graph

$$
G(w)=\left\{(t, x(t), u(t)) \mid t \in\left[t_{0}, t_{1}\right]\right\}
$$

lies in the set $Q$ with some "margin", i.e.,

$$
\begin{aligned}
& \operatorname{dist}((t, x(t), u(t)), \partial Q) \geq \text { const }>0 \\
& \text { for a.a. } t \in\left[t_{0}, t_{1}\right],
\end{aligned}
$$

or equivalently, there exists a compact set $\Omega \subset Q$ such that $(t, x(t), u(t)) \in \Omega$ for a.a. $t \in\left[t_{0}, t_{1}\right]$. A process in problem $\mathrm{A}$ is called admissible if it satisfies all the constraints of the problem.

Definition. We will say that an admissible process

$$
w^{0}(t)=\left(x^{0}(t), u^{0}(t)\right), \quad t \in\left[t_{0}, t_{1}\right]
$$

provides the weak minimum if there exists an $\varepsilon>0$ such that for any admissible process $w(t)=(x(t), u(t)), \quad t \in\left[t_{0}, t_{1}\right], \quad$ satisfying the conditions

$$
\begin{aligned}
& \left|x(t)-x^{0}(t)\right|<\varepsilon \quad \forall t, \\
& \text { and }\left|u(t)-u^{0}(t)\right|<\varepsilon \quad(\forall) t,
\end{aligned}
$$

the following inequality holds: $J(w) \geq J\left(w^{0}\right)$.

(Notation $(\forall)$ conveniently means "for almost all".)

\subsection{The local minimum principle in Problem A}

Let a process (8) provide the weak minimum in Problem A. To formulate optimality conditions, let us introduce a tuple of Lagrange multipliers corresponding to all the constraints and the cost of Problem A:

$$
\begin{aligned}
& \left(\alpha, \beta, \psi(t), h_{i}(t), m_{j}(t)\right), \\
& i=1, \ldots, d(F), j=1, \ldots, d(G),
\end{aligned}
$$

where $\quad \alpha=\left(\alpha_{0}, \alpha_{1}, \ldots, \alpha_{d(\varphi)}\right) \in \mathrm{I} R^{d(\varphi)+1} \quad$ with $\alpha_{i} \geq 0 \forall i$ (for short, we will simply write $\alpha \geq 0$ ), and $\beta=\left(\beta_{1}, \ldots, \beta_{d(\eta)}\right) \in \mathrm{I} R^{d(\eta)} \quad$ are vectors, $\psi:\left[t_{0}, t_{1}\right] \rightarrow \mathrm{I} R^{n} \quad$ is a Lipschitz continuous function,

$$
\begin{aligned}
h_{i}:\left[t_{0}, t_{1}\right] \rightarrow & \mathrm{I} R_{+}, i=1, \ldots, d(F), \quad \text { and } \\
& m_{j}: \quad\left[t_{0}, t_{1}\right] \rightarrow \mathrm{I} R, j=1, \ldots, d(G),
\end{aligned}
$$

are measurable bounded functions.

Further, introduce the Pontryagin function (or pre-Hamiltonian)

$$
\begin{aligned}
& H(t, x, u)=\psi f(t, x, u)+ \\
& +\sum_{i=0}^{d(\varphi)} \alpha_{i} \Phi_{i}(t, x, u)+\sum_{j=1}^{d(\eta)} \beta_{j} \Psi_{j}(t, x, u)
\end{aligned}
$$


(here, $\psi f$ is the product of the row and column $n$-vectors), and the augmented Pontryagin function (or augmented pre-Hamiltonian)

$$
\begin{aligned}
& \bar{H}(t, x, u)=H(t, x, u)+ \\
& +\sum_{i} h_{i} F_{i}(t, x, u)+\sum_{j} m_{j} G_{j}(t, x, u) .
\end{aligned}
$$

Also, introduce the endpoint Lagrange function

$$
l\left(x_{0}, x_{1}\right)=\left(\sum_{i=0}^{d(\varphi)} \alpha_{i} \varphi_{i}+\sum_{j=1}^{d(\eta)} \beta_{j} \eta_{j}\right)\left(x_{0}, x_{1}\right) .
$$

Both these functions refer to the tuple (10).

The functions $H, \bar{H}, l$ will be used in formulation of optimality conditions.

For the process (8) and tuple (10) with the specified properties, let us formulate the conditions of local minimum principle (or the stationarity conditions):

a) the nonnegativity conditions

$$
\alpha \geq 0, \quad h_{i}(t) \geq 0, \quad i=1, \ldots, d(F),
$$

b) the nontrivality condition

$$
|\alpha|+|\beta|+\sum_{i} \int_{t_{0}}^{t_{1}} h_{i}(t) d t>0,
$$

c) the complementary slackness conditions

$$
\begin{aligned}
& \alpha_{i}\left(\phi_{i}\left(x^{0}\left(t_{0}\right), x^{0}\left(t_{1}\right)\right)+\right. \\
& \left.+\int_{t_{0}}^{t_{1}} \Phi_{i}\left(t, x^{0}(t), u^{0}(t)\right) d t\right)=0, \\
& i=1, \ldots, d(\varphi),
\end{aligned}
$$

d) the pointwise complementary slackness conditions

$$
\begin{gathered}
h_{i}(t) F_{i}\left(t, x^{0}(t), u^{0}(t)\right)=0 \quad \begin{array}{r}
\text { a.e. } \quad \text { on }\left[t_{0}, t_{1}\right], \\
i=1, \ldots, d(F),
\end{array}
\end{gathered}
$$

e) the adjoint equation

$$
-\frac{d \psi(t)}{d t}=\bar{H}_{x}\left(t, x^{0}(t), u^{0}(t)\right)
$$

f) the transversality conditions

$$
\begin{aligned}
& \psi\left(t_{0}\right)=-l_{x_{0}}\left(x^{0}\left(t_{0}\right), x^{0}\left(t_{1}\right)\right), \\
& \psi\left(t_{1}\right)=l_{x_{1}}\left(x^{0}\left(t_{0}\right), x^{0}\left(t_{1}\right)\right),
\end{aligned}
$$

g) the stationarity condition of the extended Pontryagin function with respect to the control

$$
\bar{H}_{u}\left(t, x^{0}(t), u^{0}(t)\right)=0 \quad \text { a.e. on }\left[t_{0}, t_{1}\right] .
$$

The main result of this section is the following Theorem 1. If a process $w^{0}(t)=\left(x^{0}(t), u^{0}(t)\right)$, $t \in\left[t_{0}, t_{1}\right]$ provides the weak minimum in Problem A and satisfies assumption RMC, then there exists a tuple of multipliers $\left(\alpha, \beta, \psi, h_{i}, m_{j}\right)$ satisfying the specified above properties and such that conditions a) - $g$ ) of the local minimum principle hold true.

The proofs can be found in the book [3]. This book also contains further results of that kind, namely: the first-order conditions for a strong local minimum in the form of Pontryagin minimum principle. Moreover, along with regular mixed state-control constraints, the problem can also allow pure state constraints, and the time interval can be both fixed and variable.

\section{OPTIMAL CONTROL PROBLEM WITH VOLTERRA-TYPE INTEGRAL EQUATIONS ON A FIXED TIME INTERVAL}

\subsection{Statement of the problem (Problem B)}

We consider the following control system of Volterra-type integral equations on a fixed time interval $\left[t_{0}, t_{1}\right]$ :

$$
x(t)=x\left(t_{0}\right)+\int_{t_{0}}^{t} f(t, s, x(s), u(s)) d s
$$


Local Minimum Principle for Optimization Problems with Different Types of Control Systems Subject to Mixed State-Control Constraints

where $x(\cdot)$ is a continuous $n$-dimensional and $u(\cdot)$ a measurable essentially bounded $r-$ dimensional vector-function on $\left[t_{0}, t_{1}\right]$. Again, we call $x$ the state variable and $u$ the control variable. We assume for simplicity that the function $t$ is defined and twice continuously differentiable on an open set $R \subset \mathrm{I} R^{2+n+r}$.

The problem is to minimize the Bolza-type cost functional (2) on the set of solutions of system (19) satisfying the Bolza-type constraints (3), (4) and the mixed state-control constraints (5), (6), where the functions $\varphi_{0}, \varphi_{i}, \eta_{j}$ are defined and continuously differentiable on an open set $P \subset \mathrm{I} R^{2 n}$, and the functions $\Phi_{i}, \Psi_{j}, F_{i}, G_{j}$ are defined and continuously differentiable on an open set $Q \subset \mathrm{I} R^{1+n+r}$.

Again, we impose the assumption RMC (on the regularity of mixed constraints), given in Section 2.1. The problem (2)-(6), (19) will be called Problem B.

Note that the function $t$ explicitly depends on two time variables, $t$ and $s$, the roles of which are essentially different. Conventionally, the variable $s$ will be called inner, while $t$ will be called outer, time variable, and one should carefully distinguish between them in further considerations. Among the four arguments of the function $t$ and its derivatives, the first argument will always be the outer and the second one the inner time variable, no matter by which letters they will be denoted.

Note also that the integral equation (19) is equivalent to the following integro-differential equation:

$$
\begin{aligned}
& \frac{d x(t)}{d t}=f(t, t, x(t), u(t))+ \\
& +\int_{t_{0}}^{t} f_{t}(t, s, x(s), u(s)) d s,
\end{aligned}
$$

where the last integral shows, in a sense, how "far" we are from an ordinary differential equation. (Here $f_{t}$ means the partial derivative of the function $f(t, s, x, u)$ with respect to the first, outer time variable $t$.) If $t$ does not depend on the outer time $t$, i.e., $f=f(s, x(s), u(s))$, then this integral disappears, and Problem B becomes a standard optimal control problem with the ODE

$$
\frac{d x(t)}{d t}=f(t, x(t), u(t))
$$

Obviously, each pair $(x(t), u(t)) \quad$ under consideration must "lie" in the domain $R$ of the function $f(t, s, x, u)$, i.e.

$$
(t, s, x(s), u(s)) \in R \quad \text { fora.e. } \quad(t, s) \in D\left[t_{0}, t_{1}\right],
$$

where $D\left[t_{0}, t_{1}\right]=\left\{(t, s): t_{0} \unlhd s \unlhd t \unlhd t_{1}\right\} . \quad$ Again, we will need even a stronger condition.

Definition. A pair of functions $w(t)=(x(t), u(t))$ defined on an interval $t \in\left[t_{0}, t_{1}\right]$ (with continuous $x(t)$ and measurable essentially bounded $u(t)$ ) will be called a process in Problem B if it satisfies (19) and its "extended graph"

$$
G(w)=\left\{(t, s, x(s), u(s)):(t, s) \in D\left[t_{0}, t_{1}\right]\right\}
$$

lies in the set $R$ with some "margin"', i.e.,

$$
\begin{aligned}
& \operatorname{dist}((t, s, x(s), u(s)), \partial R) \text { const }>0 \\
& \text { fora.a. }(t, s) \in D\left[t_{0}, t_{1}\right],
\end{aligned}
$$

or equivalently, there exists a compact set $\Omega \subset R$ such that $(t, s, x(s), u(s)) \in \Omega$ for a.a. $(t, s) \in D\left[t_{0}, t_{1}\right]$. A process in problem B is called admissible if it satisfies all the constraints of the problem.

The notion of a weak local minimum in Problem $\mathrm{B}$ is the same as that in Problem A.

\subsection{The local minimum principle in Problem $B$ Let a process}

$$
w^{0}(t)=\left(x^{0}(t), u^{0}(t)\right), \quad t \in\left[t_{0}, t_{1}\right]
$$


provide the weak minimum in Problem B.

To formulate optimality conditions, let us introduce a tuple (10) of Lagrange multipliers corresponding to all the constraints and the cost of Problem B:

$$
\begin{aligned}
& \left(\alpha, \beta, \psi(t), h_{i}(t), m_{j}(t)\right), \\
& i=1, \ldots, d(F), j=1, \ldots, d(G),
\end{aligned}
$$

where, as in Section 2.2, $\alpha=\left(\alpha_{0}, \alpha_{1}, \ldots, \alpha_{d(\varphi)}\right) \in \mathrm{I} R^{d(\varphi)+1}$ with $\alpha_{i} \geq 0 \quad \forall i$ and $\beta=\left(\beta_{1}, \ldots, \beta_{d(\eta)}\right) \in \mathrm{I} R^{d(\eta)} \quad$ are $\quad$ vectors, $\psi:\left[t_{0}, t_{1}\right] \rightarrow \mathrm{I} R^{n} \quad$ is a Lipschitz continuous function, ( $\psi$ is a row $n$-vector),

$$
\begin{aligned}
& h_{i}:\left[t_{0}, t_{1}\right] \rightarrow \mathrm{I} R_{+}, i=1, \ldots, d(F), \quad \text { and } \\
& \qquad m_{j}:\left[t_{0}, t_{1}\right] \rightarrow \mathrm{I} R, j=1, \ldots, d(G),
\end{aligned}
$$

are measurable bounded functions. In what follows, all pointwise relations involving continuous functions hold for any $t$, and those involving measurable functions hold for almost all $t$.

Further, introduce the modified Pontryagin function

$$
\begin{aligned}
& H(t, s, x, u)=\psi(t) f(t, s, x, u)+ \\
&+\int_{t}^{t_{1}} \psi(\tau) f_{t}(\tau, s, x, u) d \tau \\
&+\sum_{i=0}^{d(\varphi)} \alpha_{i} \Phi_{i}(s, x, u)+\sum_{j=1}^{d(\eta)} \beta_{j} \Psi_{j}(s, x, u)
\end{aligned}
$$

and the augmented (or extended) modified Pontryagin function

$$
\begin{gathered}
\bar{H}(t, s, x, u)=H(t, s, x, u) \\
+\sum_{i} h_{i}(t) F_{i}(s, x, u)+\sum_{j} m_{j}(t) G_{j}(s, x, u) .
\end{gathered}
$$

Again, introduce the endpoint Lagrange function (13). Both these functions refer to the tuple (10). In Problem B, for the process (8) and tuple (10) with the specified properties, let us formulate the conditions of local minimum principle (or the stationarity conditions): a') the nonnegativity conditions (14), b') the nontrivality condition $\left.(15), c^{\prime}\right)$ the complementary slackness conditions (16), d') the pointwise complementary slackness conditions (17), e') the adjoint equation

$$
-\dot{\psi}(t)=\bar{H}_{x}\left(t, t, x^{0}(t), u^{0}(t)\right),
$$

$\left.f^{\prime}\right)$ the transversality conditions (18), g') the stationarity condition of the extended Pontryagin function with respect to the control

$$
\bar{H}_{u}\left(t, t, x^{0}(t), u^{0}(t)\right)=0 \quad \text { a.e.on }\left[t_{0}, t_{1}\right] .
$$

The main result of this section is the following Theorem 2. If a process $w^{0}(t)=\left(x^{0}(t), u^{0}(t)\right)$, $t \in\left[t_{0}, t_{1}\right]$ provides the weak minimum in Problem $B$ and satisfies assumption RMC, then there exists a tuple of multipliers $\left(\alpha, \beta, \psi, h_{i}, m_{j}\right)$ satisfying the specified above properties and such that conditions $\left.a^{\prime}\right)--g^{\prime}$ ) of the local minimum principle hold true.

The proof of this theorem (for a more general problem, with pure state constraints) is given in [4].

In the next section we formulate an abstract Lagrange multiplies rule which can be used for the proofs of Theorems q1 and 2.

\section{AN ABSTRACT LAGRANGE MULTIPLIERS THEOREM}

Let $X, Y$, and $Z_{i}, i=1, \ldots, v$ be Banach spaces, $D \subset X$ an open set, and $K_{i} \subset Z_{i}, i=1, \ldots, v$ closed convex cones with nonempty interiors.

Let $F_{0}: D \rightarrow \mathrm{I} R, g: D \rightarrow Y$, and $f_{i}: D \rightarrow Z_{i}$, $i=1, \ldots, v$, be given mappings. Consider the following optimization problem:

$$
\begin{aligned}
& F_{0}(x) \rightarrow \min , \quad f_{i}(x) \in K_{i}, \\
& i=1, \ldots, v, \quad g(x)=0 .
\end{aligned}
$$


Local Minimum Principle for Optimization Problems with Different Types of Control Systems Subject to Mixed State-Control Constraints

Let $\quad K_{i}^{0}:=\left\{z_{i}^{*} \in Z_{i}^{*}:\left\langle z_{i}^{*}, z_{i}\right\rangle \square 0\right.$ foreveryz $\left._{i} \in K_{i}\right\} \quad$ be the polar cone to $K_{i}, i=1, \ldots, v$. Here $\left\langle z_{i}^{*}, z_{i}\right\rangle$ is the duality pairing between $Z_{i}$ and its dual space $Z_{i}^{*}$. We study the local minimality of an admissible point $x^{0} \in D$.

It is worth noting that the inequality constraints $f_{i}(x) \leq 0$, where $f_{i}: D \rightarrow \mathrm{I} R$ are given functionals, may also be presented in the form $f_{i}(x) \in K_{i}$ if we put $K_{i}=\mathrm{I} R_{-}:=(-\infty, 0]$. Then $K_{i}^{0}=\mathrm{I} R_{+}:=[0, \infty)$.

We impose the following

\section{Assumptions.}

1. The objective function $F_{0}$ and the mappings $f_{i}$ are Fréchet differentiable at $x_{0}$; the operator $g$ is has a Frechet derivative in a neighborhood of $x_{0}$ and this derivative is continuous at $x_{0}$ (smoothness of the data functions),

2. the image of the derivative $g^{\prime}\left(x_{0}\right)$ is closed in $Y$ (weak regularity of equality constraint). The following theorem gives necessary conditions for a point $x_{0} \in D$ to be a local minimizer for problem (24).

Theorem 3. Let $x_{0}$ provide a local minimum in problem (24). Then there exist Lagrange multipliers

$$
\alpha_{0} \geq 0, z_{i}^{*} \in K_{i}^{0}, i=1, \ldots, v, \text { and } y^{*} \in Y^{*} \text {, }
$$

satisfying the nontriviality condition

$$
\alpha_{0}+\sum_{i=1}^{v}\left\|z_{i}^{*}\right\|+\left\|y^{*}\right\|>0
$$

the complementary slackness conditions

$$
\left\langle z_{i}^{*}, f_{i}\left(x_{0}\right)\right\rangle=0, \quad i=1, \ldots, v,
$$

and such that the Lagrange function

$$
L(x)=\alpha_{0} F_{0}(x)+\sum_{i=1}^{v}\left\langle z_{i}^{*}, f_{i}(x)\right\rangle+\left\langle y^{*}, g(x)\right\rangle
$$

is stationary at $x_{0}: L^{\prime}\left(x_{0}\right)=0$. i.e.,

$$
\alpha_{0} F_{0^{\prime}}\left(x_{0}\right)+\sum_{i=1}^{v}\left\langle z_{i}^{*}, f_{i^{\prime}}\left(x_{0}\right)\right\rangle+\left\langle y^{*}, g^{\prime}\left(x_{0}\right)\right\rangle=0 \text {. }
$$

This theorem is an efficient tool for a wide range of optimization problems with an infinite number of constraints. Its proof, based on the so-called Dubovitskii--Milyutin approach [1], can be found in $[3,4,5]$.

In a particular case when $Y=\mathrm{I} R^{n}$, Assumption 2 is valid automatically, and $y^{*}=\left(\beta_{1}, \ldots, \beta_{n}\right)$ is an $n$-dim vector.

\section{ACKNOWLEDGEMENTS}

This work was supported by Russian Foundation for Basic Research under grant 16-01-00585.

\section{REFERENCES}

1. Dubovitskii A.Ya., Milyutin A.A. Extremum Problems in the Presence of Restrictions. // Zh. Vychisl. Mat. Mat. Fiz., USSR Comput. Math. and Math. Phys., 1965, 5(3), pp. 1-80.

2. Afanasjev A.P., Dikusar V.V., Milyutin A.A., Chukanov S.A. Nieobhodimoe Uslovie v Optimalnom Upravlenii. Moscow, Nauka, 1990.

3. Milyutin A.A., Dmitruk A.V., Osmolovskii N.P. Princip Maksimuma v Optimal'nom Upravlenii [Maximum Principle in Optimal Control]. Moscow, Lomonosov Moscow State University, Faculty of Mechanics and Mathematics, Moscow, 2004 (in Russian), 168 pages.

4. Dmitruk A.V., Osmolovskii N.P. Necessary Conditions for a Weak Minimum 
in Optimal Control Problems with Integral Equations Subject to State and Mixed Constraints. // SIAM J. on Control and Optimization, 2014, Volume 52, pp. 34373462.

5. Dmitruk A.V., Osmolovskii N.P. A General Lagrange Multipliers Theorem and Related Questions, Springer (submitted).

\section{СПИСОК ЛИТЕРАТУРЫ}

1. Dubovitskii A.Ya., Milyutin A.A. Extremum Problems in the Presence of Restrictions. // Zh. Vychisl. Mat. Mat. Fiz., USSR Comput. Math. and Math. Phys., 1965, 5(3), pp. 1-80.

2. Афанасьев А.П., Дикусар В.В., Милютин А.А., Чуканов С.В. Необходимое условие в оптимальном управлении. - М.: Наука, 1990. - 320 с.

3. Милютин А.А., Дмитрук А.В., Осмоловский Н.П. Принцип максимума в оптимальном управлении. - М.: Издательство ЦПИ при механико-математическом факультете МГУ им. М.В. Ломоносова, 2004. - 168 c.

4. Dmitruk A.V., Osmolovskii N.P. Necessary Conditions for a Weak Minimum in Optimal Control Problems with Integral Equations Subject to State and Mixed Constraints. // SIAM J. on Control and Optimization, 2014, Volume 52, pp. 34373462.

5. Dmitruk A.V., Osmolovskii N.P. A General Lagrange Multipliers Theorem and Related Questions, Springer (submitted).

Andrey V. Dmitruk, Professor, Dr.Sc., Russian Academy of Sciences, CEMI, Moscow, Russia; Lomonosov Moscow State University, Moscow, Russia;

E-mail:dmitruk@member.ams.org

Nikolay P. Osmolovski, Professor, Dr.Sc., University of Technology and Humanities in Radom, Poland; Systems Research Institute, Polish Academy of Sciences War- szawa, Poland; National Research Moscow State University of Civil Engineering, Moscow, Russia; 26, Yaroslavskoe Shosse, Moscow, 129337, Russia; тел.+7(499)183-59-94; e-mail: osmolovski@uph.edu.pl.

Дмитрук Андрей Венедиктович, профессор, доктор физико-математических наук; профессор кафедры оптимального управления Московского государственного университета им. М.В. Ломоносова; ведущий научный сотрудник Центрального экономико-математического институт Российской академии наук; E-mail:dmitruk@member.ams.org.

Осмоловский Николай Павлович, профессор, доктор физико-математических наук; профессор кафедры прикладной математики Национального исследовательского Московского государственного строительного университета; 129337, Россия, г. Москва, Ярославское шоссе, дом 26; phone +7(499)183-59-94;

E-mail: osmolovski@uph.edu.pl. 